\title{
Drug-eluting coronary stents: faith and hope, but no charity
}

\author{
Merril L. Knudtson
}

Published at www.cmaj.ca on Dec. 19, 2006. Revised on Dec. 28, 2006.

$\infty \quad$ See related articles, pages I85 and I99

J udging from the large number of publications on the cost-effectiveness of drug-eluting coronary stents, there is an emerging international consensus that the price tag for the 2 commercially available drug-eluting stents is excessive (approximately $\$ 1500$ to $\$ 3000$ per stent in Canada). Why is the price so high? What motivates cardiac centres around the world to continue to buy them in large volumes? The answers to these questions are, in large part, rooted in the very history of the percutaneous coronary intervention (PCI) procedure and in the funding model for the development of new technologies that exists in most of the developed world.

Despite the phenomenal international acceptance of PCI over the past 3 decades, strong scientific support for PCI usage patterns has been elusive. Indeed, the interventional community is often accused of making decisions based on faith more than on fact. Even confirmation of PCI use in selected high-risk patients with acute coronary syndromes was a relatively recent development. ${ }^{1}$

Since the very beginning, restenosis and the associated need for revascularization have been responsible for tainting PCI performance in clinical trials. ${ }^{2}$ In 1994, bare-metal stents were introduced to eliminate elastic recoil and stabilize plaque disarray after balloon interventions. These devices lowered the need for repeat interventions in target vessels from $25 \%$ to $13 \%{ }^{3}$ - a significant but only partial success in the war on restenosis. The introduction of drug-eluting stents in 2002 in Europe and Canada and in 2003 in the United States further lowered the need for revascularization in target vessels to the more comfortable rate of $4 \%$. ${ }^{3,4}$

Health care professionals who lived through the long restenosis "pandemic" would find it difficult to reject this apparent cure for restenosis, despite the imposing price tag for drug-eluting stents. Most interventional cardiologists possess the abiding hope that an end to the problem of restenosis will open a new era, one in which patients with more complex and diffuse coronary artery disease will be successfully treated with PCI.

In this issue of $C M A J, 2$ articles provide important insights into the use of drug-eluting stents. In the first, Grilli and sponding PCI and cardiac surgery rates in public and private hospitals in the Emilia-Romagna region of Italy. ${ }^{5}$ They found that public hospitals were more selective than private facilities in their use of these stents and appeared to acknowledge the advantages of the new technology by shifting relative cardiac surgery and PCI numbers in favour of PCI. Interestingly, it is the Italian private sector that has adopted unrestricted use of drug-eluting stents without a change in overall cardiac surgery volumes. Although the number of isolated CABG procedures decreased in both the private and public hospitals, the level of reduction was significantly greater in the public hospitals. The small reduction in the private hospitals suggests a reluctance to move from CABG and the high revenues it generates to PCI and its lower revenue margins due to the high cost of drug-eluting stents. That PCI numbers did not decrease was likely a business decision to maintain a "high technology veneer" that would appeal to patients and referring physicians. ${ }^{5}$

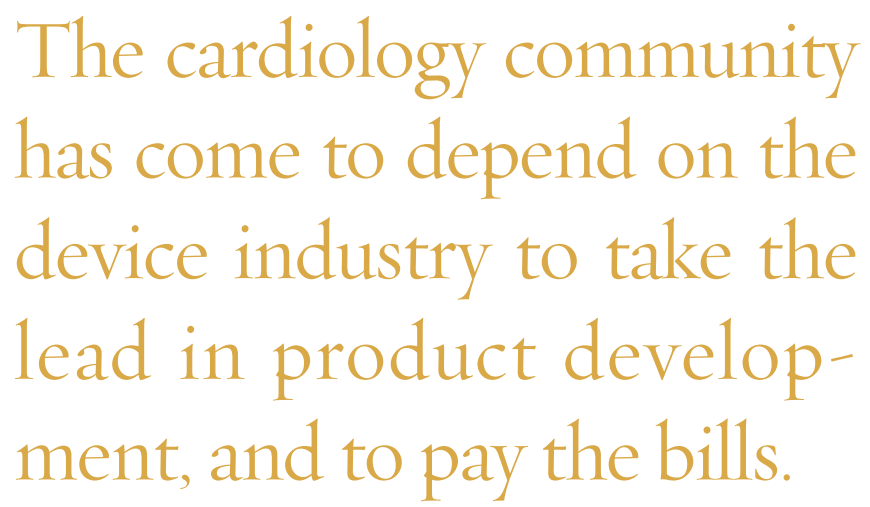

In the second article, Ligthart and coauthors conducted an excellent and careful systematic review of the many costeffectiveness analyses comparing drug-eluting and baremetal stents published over the last 3 years. ${ }^{6}$ They found that the studies had different methodologies and often divergent conclusions. Ligthart and coauthors rated the quality of the studies using an instrument consisting of $\mathrm{I} 6$ equally weighted and validated cost-effectiveness analysis parameters. The papers of highest quality were consistent in their support of a more selective use of drug-eluting stents. The review, however, failed to emphasize that the perspective of a costeffectiveness analysis (society, hospital, third-party payer) can lead to different conclusions, as illustrated by the CABG and PCI balance in the Italian private sector. ${ }^{5}$ Nevertheless, the review by Ligthart and coauthors will serve to raise the bar of quality for publications purporting to comment on issues of cost and quality of care. ${ }^{6}$

Ligthart and coauthors also found that the studies of highest quality were those that did not receive sponsorship from manufacturers of drug-eluting stents. Indeed, it is not likely that industry can ever be totally objective in discussions in- 
volving product costs. Nevertheless, it would be wise to reflect on some realities of new technology development.

Because alternative sources of funding for development of new technologies are few, the cardiology community has come to depend on the device industry to take the lead in new product development, and to pay the bills. Depending on one's point of view, this relationship could be classified as Faustian. Others would hold that consumer indignation over the cost of new technology reflects naïveté concerning the business world. Indeed, all regulatory agencies are demanding larger clinical trials for drug-related devices, and unexpected developments can dramatically alter product life cycles and the possibility of cost recovery. ${ }^{7}$

To ensure that full value is received in the quest for new technologies, a thoughtful surveillance system of the nature of clinical practice change and whether outcome is thereby improved is critical. ${ }^{8}$ From one American registry that was not part of a clinical trial, ${ }^{9}$ the use of drug-eluting stents appears to be having a measurable impact on revascularization decision-making, as was also reported in the Italian public sector. ${ }^{5}$

The 2 articles in this issue of CMAJ support the conclusion that operative incentives remain misaligned among the principal stakeholders (patients, physicians, payers, policymakers and industry). We can choose to be cynical about this, or we can try to understand why this is and promote change.

Charity from the business sector is unlikely. Hospitals worldwide have been willing to pay the sticker price for drugeluting stents, motivated by the faith that the long-standing problem of restenosis has been solved and a hope that even greater technologic advances are ahead of us.

There is also hope that the debate over drug-eluting stents has awakened fiscal awareness on many levels, and more importantly the need for industry to abandon a "whatever the market will bear" pricing strategy. In turn, the cardiology community can take greater responsibility for its clinical decisions. To illustrate this, the recently presented Occluded Artery Trial (OAT) has successfully challenged the long- standing belief that an open artery is always desirable even late in the course of a myocardial infarction. ${ }^{10}$ Even stricter patient selection and active promotion of therapies proven to be effective would lead to improved patient care and truly major cost savings. These outcomes indeed would be "gifts that keep on giving" for our health care system.

This article has been peer reviewed.

Merril Knudtson is with the Libin Cardiovascular Institute of Alberta, University of Calgary, Calgary, Alta.

Competing interests: None declared.

\section{REFERENCES}

I. Keeley EC, Boura JA, Grines CL. Primary angioplasty versus intravenous thrombolytic therapy for acute myocardial infarction: a quantitative review of 23 randomised trials. Lancet 2003;361:13-20.

2. Serruys PW, Ong ATL, van Herwerden LA, et al. Five-year outcomes after coronary stenting versus bypass surgery for the treatment of multi-vessel disease: The fina analysis of the Arterial Revascularization Therapies Study (ARTS) randomized trial. J Am Coll Cardiol 2005;46:575-8I.

3. Hodgson JM, Bottner RK, Klein LW, et al. A. Drug-eluting stent task force: final report and recommendations of the working committees on cost-effectiveness/economics, access to care and medicolegal issues. Catheter Cardiovasc Interv 2004;62:I-I7.

4. Eisenberg MJ. Drug-eluting stents: The price is not right. Circulation 2006;II4 I745-54.

5. Grilli R, Guastaroba P, Taroni F. Effect of hospital ownership status and payment structure on the adoption and use of drug-eluting stents for percutaneous coronary interventions. CMAJ 2007;176(2):185-90.

6. Ligthart S, Vlemmix F, Dendukuri N, et al. The cost-effectiveness of drug-eluting stents: a systematic review. CMAJ 2007;176(2):199-205.

7. Shuchman M. Trading restenosis for thrombosis? New questions about drugeluting stents. N Engl J Med 2006;355:I949-52.

8. Fox KAA. Registries and survers in acute coronary syndrome. Eur Heart J 2006;27: 2260-2.

9. Williams DO, Dawn AJ, Kip KE. for the DEScover Investigators. Outcomes of 6906 patients undergoing percutaneous coronary intervention in the era of drug-eluting stents: report of the DEScover Registry. Circulation 2006;114:2154-62.

Io. Hochman JS, Lamas GA, Buller CE, et al.; Occluded Artery Trial Investigators. Coronary intervention for persistent occlusion after myocardial infarction. $N$ EngIJ Med 2006;355:2395-407.

Correspondence to: Dr. Merril L. Knudtson, Foothills Medical Centre, University of Calgary, Rm. C849, I403-29 St. NW, Calgary $A B$ T2N 2T9; mlknudts@ucalgary.ca 